\title{
WALTER BENJAMIN: Inspirações para a Historiografia da Educação
}

WALTER BENJAMIN: Inspirations for the Historiography of the Education

Rafael Alexandre Belo ${ }^{1}$

\begin{abstract}
RESUMO:
O presente artigo tem o objetivo de apresentar princípios metodológicos e proposições teóricas para a história da educação a partir da leitura de Walter Benjamin. Consideramos como alicerces epistemológicos da presente construção: a concepção de tempo (Jetztzeit); a dimensão teológica; a concepção de história; a crítica ao progresso; e a concepção de experiência (Erfahung). A articulação desses princípios como elementos metodológicos demonstrou ser uma importante contribuição para investigações de grupos silenciados pela história oficial.

Palavras-chave: História da Educação; Historiografia; Walter Benjamin.
\end{abstract}

\section{ABSTRACT:}

This article aims to present theoretical propositions and methodological principles to the history of education from the reading of Walter Benjamin. We consider epistemological foundations of this construction: the concept of time (Jetztzeit); the theological dimension; the concept of history; the critique of progress; and the concept of experience (Erfahung). The articulation of these principles as elements of methodology and proved an important contribution to research groups silenced by official history.

Keywords: History of Education; Historiography; Walter Benjamin.

\section{Prelúdio de uma caminhada}

A escrita de Benjamin sempre despistou olhares por demais objetivistas ou de fundo cegamente marxista. No mosaico de seus escritos há um modo aberto e inconcluso de se expressar, linearidade e sistematização experimentais, um espírito criativamente revolucionário, com fortes implicações políticas de inspiração teológica. Estas nobres características talvez sirvam para preservar seus textos de conclusões precipitadas, que não se dispõem a compreender o que é anunciado.

Alemão de origem judaica foi considerado o primeiro crítico literário de seu país de origem. Benjamin é um dos mais notáveis intelectuais do século XX (1892-1940), autor de uma obra tão profunda quanto diversificada. "Sua reflexão constitui um todo no qual arte, história, cultura, política, literatura e teologia são inseparáveis" (LÖWY, 2005, p.14). Integrando a escola de Frankfurt, contribuiu com Adorno, Horkeimer e Marcuse na elaboração de uma crítica à cultura e à modernidade.

Há uma tendência a considerá-lo um historiador da cultura (LÖWY, 2005). "Teses sobre o conceito de história" (BENJAMIN, 2004b), escrito em 1940, é encarado como um dos textos filosóficos e políticos mais importantes do século XX. Para Löwy (2005), este é o documento mais significativo desde as "Teses sobre Feuerbach" de Marx.

1 Psicólogo especialista em Psicologia e Ação Psicossocial. Mestrando em Educação Brasileira pela Universidade Federal de Alagoas. Bolsista da FAPEAL. Professor do Departamento de Psicologia da Ufal. 
Walter Benjamin é um pensador polêmico e muito mal compreendido, mesmo na atualidade. Uma das origens da dificuldade de interpretá-lo está na pouca disposição, que em geral se tem, em articular, em seu pensamento, a dimensão teológica, de inspiração místicojudaica, e a dimensão política, de influência marxista. "Um pensamento inovador, original, inclassificável, que se caracteriza pelo que ele chama, numa carta a Sholem de maio de 1926, de 'paradoxal reversibilidade recíproca' (Umschlagen) do político no religioso e vice-versa" (LÖWY, 2005, p.36-37).

A incompreensão da obra de Benjamin acompanhará todos aqueles que, não se dispondo a "caminhar" pela complexidade de seus textos, buscarem neles apenas informações. Por outro lado, vendo-se a obra de Benjamin como uma "grande passagem", vê-se também que é preciso "saber caminhar", já que seus passos estão intimamente relacionados com sua alma, olhar e mão. A visão apenas panorâmica não garante a riqueza, que só os detalhes nos fornecem; deixa-o como uma referência distante. Tal atitude é como perdermos os detalhes de uma arquitetura que nos conta segredos de uma época que ecoa nos passos do presente.

De modo semelhante, o olhar por demais objetivista produz certa cegueira branca. Tanta luz absorve o olhar ávido por informação. A fixação pelo detalhe de qualquer construção de nosso interesse nos faz entorpecidos, desvinculados da sensação de fazer parte da paisagem, composta pelas palavras de todos os outros elementos que nos cercam. "Qual o valor do nosso patrimônio cultural, se a experiência não se vincula a nós?" (BENJAMIN, 1994a, p.115).

De fato não conseguimos enxergar nada que não se vincule àquilo que somos. Existe um sentido em questão, necessário para a narração daquilo que nos chega como experiência. Aquilo que vemos é também uma produção nossa, em uma dimensão que ao mesmo tempo é individual e coletiva. Entendemos, então, por que a cidade preserva traços de um modo de vida em sua materialidade.

Reconhecemos que muitos são os olhares pobres em experiências que vão para além da nossa individualidade. Alguns olhares são destruidores da arquitetura da cidade, da história, da obra de um pensador que entendeu a mística relação entre passado, presente e futuro. Por isso tais olhares precisam ser despistados. E para isso o autor precisou escrever com arte e estilo.

Aqui procuro trazer um olhar sobre as contribuições do autor para se pensar uma metodologia historiográfica. Nosso objetivo é, portanto, a partir da inspiração de Benjamin, apresentar considerações acerca do uso do método e fonte de pesquisa em História da Educação. A intenção de sistematizar um olhar referente aos aspectos metodológicos é fruto de quem caminha com interesse pelos rastros desse autor, e brota, também, da percepção da 
necessidade existente na História da Educação de se explicitar como o pensamento de Benjamin pode contribuir para o fazer historiográfico. ${ }^{2}$

O presente texto será dividido em quatro partes. Inicialmente apresentamos considerações sobre a Historiografia e Benjamin. No segundo momento apresentamos uma discussão sobre algumas concepções que entendemos serem alicerces epistemológicos na compreensão de uma construção metodológica a partir de Benjamin, tal qual a concepção de tempo, de teologia, de história, a crítica ao progresso, a concepção de experiência. No item terceiro, procuramos objetivar as implicações de tais conceitos sobre uma construção metodológica para a História da Educação. Em seguida discorremos sobre a educação que pode ser tanto um instrumento da barbárie, como pode surgir historicamente com uma força redentora. Por fim, concluímos o texto ("Acerca do caminho experimentado") considerando as contribuições metodológicas aqui apresentadas como merecedoras de sucessivas re-invenções.

\section{A Historiografia e Benjamin}

Em setembro do corrente ano (2010), faz setenta anos da morte de Benjamin. E pouco exploramos de modo mais fecundo as possibilidades de sua contribuição metodológica para a historiografia. Lutz Niethammer (apud BOLLE, 2007, p. 1.153), referindo-se aos anos de 1960 a 1980, acusa: "Como os historiadores, pelo visto, dormiram no ponto enquanto acontecia 0 debate sobre Benjamin." E acrescenta: "as propostas benjaminianas acabam faltando [...] nos esforços por uma renovação da historiografia." Segundo Bolle (2007, p.1.153), os próprios benjaminianos têm dificultado esta aproximação: "(...) não são poucos os benjaminianos que mantêm o 'seu' autor isolado dos debates sobre a nova historiografia e se enclausuram em sua terminologia idiossincrática, como se fosse reservada somente para uns poucos iniciados."

$\mathrm{Na}$ História da Educação, mais especificamente, uma das poucas autoras que abordam uma discussão sobre Benjamin é Clarissa Nunes (2005); contudo, não o faz no sentido de uma metodologia historiográfica, e sim de uma discussão sobre a relação entre a razão benjaminiana e a educação.

\footnotetext{
Educadores inspirados em Benjamin trabalham a partir da abundância de ser e do limite de estar encarnado. Trabalham com nuanças. Trabalham com o provisório. Trabalham por dentro de uma dinâmica integradora do que é, do que foi, do que virá. Trabalham com a atemporalidade no tempo, com o ilimitado no limite, com a beleza, não no sentido do bonito ou do feio, mas do íntegro. Convocam a uma reeducação (NUNES, 2005, p. 97).
}

\footnotetext{
2 As reflexões que serão aqui expostas fazem parte da construção do referencial metodológico da pesquisa "A história da educação em Alagoas a partir dos terreiros de xangô de Maceió: da memória à narrativa e sua construção histórica". Pesquisa vinculada ao programa de mestrado em educação brasileira da Universidade Federal de Alagoas.
} 
É verdade que Benjamin é citado em diversos trabalhos nos congressos, como na última edição do Congresso Brasileiro de História da Educação e nas últimas edições do Congresso Internacional de Pesquisa (Auto) Biográfica. Contudo, não observamos a demonstração de um conhecimento mais aprofundado sobre as questões metodológicas.

O campo teórico e a consequente construção do método está necessariamente relacionado a questões mais amplas da própria concepção metodológica. Quando falamos de metodologia, nos referimos a algo mais complexo do que uma mera receita pragmática de como realizar uma pesquisa. Por sua vez, trabalhar uma metodologia cria a necessidade de discutir questões outras que são de base epistemológica. Ou seja, remete necessariamente a alicerces que sustentam a construção do conhecimento, tal qual uma visão de mundo, de ser humano, de tempo, de sociedade, de política.

Para inserir Benjamin no debate historiográfico um ponto precisa ser frisado como fundante: a sua concepção antievolucionista da história, que se desdobra na intenção de desconstruir a historiografia convencional. Para Bolle (2007), dois termos servem de ponte entre a terminologia benjaminiana e a nomenclatura dos estudos históricos: a crítica ao conceito de progresso nos moldes modernos e a crítica do método genético-causal.

Em relação a este último Benjamin comenta:

O historicismo se contenta em estabelecer um nexo causal entre vários momentos da história. Mas nenhum fato, meramente por ser causa, é só por isso um fato histórico. Ele se transforma em fato histórico postumamente, graças a acontecimentos que podem estar dele separados por milênios (BENJAMIN, 1994, p. 232).

Ao rejeitar os pontos cristalizados pela causalidade histórica, Benjamin valoriza o poder interpretativo do historiador, que dá sentido ao tempo a partir do seu presente. Este presente não pode fazer parte de uma ideia de progresso, sob o risco de se instalar a fatalidade no trato do tempo histórico e incentivar uma postura apolítica e conformista.

$\mathrm{O}$ texto onde encontramos a crítica de Benjamin à historiografia tradicional e ao mesmo tempo elementos para uma inovação historiográfica é aquele que foi o último a ser escrito e que só foi publicado após sua morte: "Teses sobre o conceito de história" (BENJAMIN, 2004b). Este documento foi enviado para alguns amigos próximos, como Hannah Arendt e Adorno, e o próprio autor insistia que não se destinava a publicação, pois isto abriria portas para a "incompreensão entusiasta" (LÖWY, 2005).

"O estímulo direto para a redação das teses foi, sem dúvida, o pacto germano-sociético, o começo da Segunda Guerra Mundial e a ocupação da Europa pelas tropas nazistas" (LÖWY, 2005, p.34). Benjamin critica a historiografia "progressista", concepção em vigor na social- 
democracia alemã, que traz a ideia de um progresso inevitável e cientificamente previsível; e a historiografia "burguesa", ou seja, o historicismo, oriundo da grande tradição acadêmica de Ranke e Dilthey, em sua intenção de apontar uma imagem eterna do passado (GAGNEBIN, 1994). De acordo com Gagnebin (1994), essas duas tradições historiográficas, a burguesa e a progressista, apoiam-se em uma concepção de tempo linear, cronológico. Em oposição, Benjamin funda outra noção um tempo (Jetztzeit), "caracterizado por sua intensidade e sua brevidade, cujo modelo foi explicitamente calcado na tradição messiânica e mística judaica" (GAGNEBIN, 1994, p.8).

A seguir iremos discutir algumas concepções que privilegiamos, por considerarmos ser alicerces epistemológicos importantes para uma construção metodológica a partir de Benjamin, iniciando por sua concepção de tempo.

\section{Alicerces Epistemológicos}

\section{1 - "Tempo do Agora" - Jetztzeit}

A forma como concebemos o tempo está intimamente ligada ao modo como vivemos a ação presente e seu potencial de construir a história. Um entendimento puramente linear, vazio do tempo, anuncia o futuro como uma consequência do passado e deixa para nós muito pouco poder de mudança. Na Tese XV, Benjamin "identifica de modo mais preciso essa temporalidade vazia: a dos relógios. Trata-se do tempo puramente mecânico, automático, quantitativo, sempre igual a si mesmo, dos pêndulos: um tempo reduzido ao espaço" (LÖWY 2005, p.125). O tempo do relógio nos rouba o poder do agora, em que reside nossa possibilidade de ação. Por isso, diante de tal linearidade, precisamos agir atemporalmente, ou seja, de modo extemporâneo, fazendo alusão ao texto de Nietzsche (2000) citado na tese XII.

A oposição ao tempo homogêneo e vazio também é realizada na tese XIV, apresentando o conceito de "tempo de agora", jetztzeit, efêmero e intenso, calcado na tradição messiânica e mística judaica. Na versão das Obras escolhidas de Benjamin, com tradução de Sérgio Paulo Rouanet, que é a mais conhecida no Brasil, a palavra alemã jetztzeit, que significa "tempo do agora" (cf. no Glossário da terminologia benjaminiana da obra Passagens), é fragmentada na frase: "A história é objeto de uma construção cujo lugar não é o tempo homogêneo e vazio, mas um tempo saturado de "agoras" (BENJAMIN, 1994, p. 229 - tese 14). Já na tradução das teses realizada por Jeanne Marie Gagnebin e Marcos Lutz Müller, utilizada na leitura de Löwy (2005), usa-se o termo "tempo-de-agora": "A história é objeto de uma construção, cujo lugar não é formado pelo tempo homogêneo e vazio, mas por aquele saturado pelo tempo-de-agora (Jetztzeit)" (BENJAMIN, apud LÖWY 2005, p.119) 
O passado contém o presente, Jetztzeit - "tempo-de-agora" ou "tempo atual". Em uma variante da tese XIV, Jetztzeit é definido como um "material explosivo" ao qual o materialismo histórico junta o estopim. Trata-se de fazer explodir o contínuo da história com ajuda de uma concepção do tempo histórico que o percebe como "pleno", carregado de momentos "atuais", explosivos, subversivos (LÖWY, 2005, p. 120).

"A consciência de fazer explodir 0 continuum da história é própria às classes revolucionárias no momento da ação" (BENJAMIN, 1994b, p. 230 - tese XV). É o "tempo-deagora" que potencializa o âmbito da ação revolucionária, esta que age contra o tempo do continuum da história. Fazemo-nos, assim, criadores da história em vez de meros repetidores ou espectadores. Em Benjamin o tempo só pode ser vivido como experiência, uma vez que é "pleno de agoras", ponto do encontro do passado, do presente e do futuro.

\section{2 - Mística Judaica}

O tempo jamais teria uma força revolucionária se, em nome do materialismo, lhe fosse negado seu caráter teológico. Na tradição mística judaica o caráter teológico da realidade não se encontra jamais fora do mundo, sendo ele capaz de renovar as forças possíveis de transformálo. Ao contrário de outras culturas, a tradição judaica não concebe Deus como algo abstrato que se encontra no além-mundo. Não é, por isso, algo que afaste o homem de sua mundanidade. Martin Buber, filósofo judeu, contemporâneo de Benjamin, explicita esta questão de modo contundente: "Aquele que verdadeiramente vai ao encontro do mundo vai ao encontro de Deus" (BUBER, 1979, p.110). Neste sentido a espiritualidade terá a ver com a força de relação com 0 mundo. Uma força geradora do diálogo (BELO, 2008). Este diálogo aparece de diferentes formas, inclusive na forma enfatizada por Benjamin, em um passado que se comunica, através das vozes que ecoam no presente. Cabe ressaltar, no entanto que Benjamin em seus escritos Benjamin não toca no nome de "Deus" e sim de "messias".

Yossef Hayim Yerushalmi (apud LÖWY, 2005, p.142) observa que o que os judeus "buscam no passado não é sua historicidade, mas sua eterna contemporaneidade." Esses elementos nos permitem entender que o sentido teológico dos escritos de Benjamin é a base estrutural da implicação política de suas ideias. Desde a primeira tese Benjamin deixa claro que a teologia tem uma importância fundante em sua perspectiva de trabalho. Para Löwy (2005, p. 45), Benjamin tem a intenção de "mostrar a complementaridade dialética entre os dois: a teologia e o materialismo histórico são ora o mestre, ora o servo; são ao mesmo tempo mestre e servo um do outro, eles precisam um do outro."

Para Benjamin, a teologia não é um objetivo em si, não visa à contemplação inefável de verdades eternas, e muito menos, como poderia a etimologia levar a 
crer, à reflexão sobre a natureza do Ser divino: ela está a serviço da luta dos oprimidos. Mais precisamente, ela deve servir para restabelecer a força explosiva, messiânica, revolucionária do materialismo histórico (LÖWY 2005, p.45).

De acordo com Löwy (2005), para entender a teologia em Benjamin é preciso remeterse a dois termos fundamentais: a rememoração (Eingedenken) e a redenção messiânica (Erlösung). "A rememoração tem por tarefa, segundo Benjamin, a construção de constelações que ligam o presente e o passado" (LÖWY, 2005, p. 131). Ela é capaz de tornar inacabado o passado, o que nos permite ouvir as vozes das vítimas do passado. Essas vozes, que ecoam na rememoração, nos atribuem a tarefa da redenção messiânica / revolucionária.

(...) existe um encontro secreto, marcado entre as gerações precedentes e a nossa. Alguém na terra está à nossa espera. Nesse caso, como a cada geração, foi-nos concedida uma frágil força messiânica para a qual o passado dirige um apelo. Esse apelo não pode ser rejeitado impunemente. 0 materialista histórico sabe disso (BENJAMIN, 1994b, p.223 - tese II).

Löwy (2005, p.51) chama a atenção de que não há um Messias enviado do céu: "somos nós o Messias, cada geração possui uma parcela do poder messiânico e deve se esforçar para exercê-la". A redenção é material e não abstrata, ela se refere a "transformações revolucionárias da vida material" (LÖWY, 2005, p.58).

\title{
2.3 - História como obra de arte
}

Por uma história que nos permita ser criadores. Que não nos conforme com a regra da história oficial: opressão, barbárie, violência dos vencedores. "A tradição dos oprimidos nos ensina que o 'estado de exceção' em que vivemos é na verdade a regra geral. Precisamos construir um conceito de história que corresponda a essa verdade" (BENJAMIN, 1994b, p. 226 tese VIII). Para Benjamin a história não tem sido outra coisa que não a história dos vencedores, um cortejo triunfante dos dominadores.

\begin{abstract}
Nesses efeitos, a história é o oposto da arte: e somente quando a história suporta ser transformada em obra de arte e, portanto, tornar-se pura forma artística, ela pode, talvez, conservar instintos ou mesmo despertá-los. Tal historiografia, porém, estaria em total contradição com o traço analítico e inartístico de nosso tempo, e até mesmo será sentida por ele como falsificação"(NIETZSCHE, 2000, p. 275).
\end{abstract}

Essa história quer nos trazer o esquecimento de todas as lutas e revoltas que quiseram interromper ou trazer para tal cortejo um estado de exceção. A história dos vencedores quer nos deixar passivos, nos afastar desse "estado de exceção", quer mesmo nos destruir enquanto seres ativos e criadores em todo processo histórico.

A única forma de não ser destruído pela história é a gente vivenciar a história como obra de arte. Ou seja, a história não é uma questão de repetição. A história não é uma questão de reprodução. A história e inclusive a memória são uma questão de criação. E ou a gente cria ou a história destrói a gente. Ou seja: ou a gente vivencia 
a história e inclusive a memória como possibilidade e cria, ou a gente simplesmente repete a história como coisa e é soterrado com uma história coisificada. Então qual é a questão fundamental? O que é importante: é repetir a história ou criar a história? (...) É repetir a história e ser soterrado pela história ou criar a história? Esta é a questão para o Nietzsche fundamentalmente. (FONSECA, 2008)

Benjamin coloca-se contrário à história oficial burguesa, normalmente encarada como uma sucessão de passados que legitimam a vitória do dominador. A opção política é por uma história daqueles que foram oprimidos, e para estes o passado não pode estar fechado, não pode ser transformado em um fato morto. O passado está vivo, lança ao presente as vozes daqueles que lutaram, clama por nossa redenção, capaz de criar um futuro que não perpetue a história do vencedor.

Na tese XVI Benjamin nos apresenta uma alegoria sobre o processo histórico. Löwy (2005, p.128) interpreta da seguinte forma:

\footnotetext{
a prostituta "era uma vez", instalada no bordel "historicismo", recebia os vencedores um após outro. Ela não tinha escrúpulos para se dar a um e, em seguida, abandoná-lo em prol do seguinte. Sua sucessão constitui o contínuo da história: era uma vez Júlio César, era uma vez Carlos Magno, era uma vez o papa Borgia e assim por diante.
}

Precisamos, pois, nos manter senhores de nossas forças criativas, "para fazer saltar pelos ares o continuum da história" (BENJAMIN, 1994, p. 231), fazer desse "estado de exceção" uma regra geral.

\section{4 - Sobre a crítica ao progresso}

Ao romper com a ilusão do progresso Benjamin (1994b) concebe o fazer histórico como algo criativo. Afirmar, assim, a força política da história é a forma que temos de impedir a consolidação da destruição pelo mito do progresso. 0 mito do progresso combina o otimismo histórico com a ausência de iniciativa, a passividade, o imobilismo. É evidente, pois, que a crítica de Benjamin não se trata de um debate puramente teórico e filosófico, trata-se de uma convocação urgente para a ação. Uma vez que não existe nada que garanta o amanhã como resultado matemático de um passado, precisamos agir historicamente. Essa crítica cabe inclusive ao marxismo vulgar, que vê, com naturalismo histórico, o fim do capitalismo seguido pelo socialismo. Sem nosso engajamento político, nenhuma transformação será possível.

A lógica do mito do progresso só pode ser uma: se tudo progride, nada temos a fazer. A crítica à ideia de progresso de Benjamin é, portanto, uma recusa à fatalidade. "A única coisa que pode vir a ser fatal ao homem é crer na fatalidade, pois esta crença impede o movimento de conversão" (BUBER, 1979, p.67). O termo conversão usado por Buber também possui uma raiz 
judaica, de forma que podemos aproximá-lo da concepção de redenção messiânica / revolucionária de Benjamin. Ao mesmo tempo que nos opomos ao mito do progresso, que recusamos a crença na fatalidade, estamos nos opondo a uma época de decadência. "A superação dos conceitos de "progresso" e de "época de decadência" são apenas dois lados de uma mesma coisa" (BENJAMIN, 2007, p. 503 - N 2,5). O que se tem chamado de progresso é uma grade expressão da barbárie, que em termos históricos significa apagar a memória dos oprimidos, juntamente com toda força revolucionária das gerações passadas. Tal esquecimento só deixaria uma opção: assumir a história como um saber teórico produzido pelos opressores, produzindo uma memória mitificada e artificial, que inibiria a ação criativa e revolucionária do presente. $O$ instrumento de luta que nos surge opera através do esquecimento das memórias que nos são impostas de modo determinista e da recuperação da capacidade de criar memórias, assim como o passado e a própria história.

O materialismo histórico assumido por Benjamin aniquila a ideia de progresso, toma a atualização como conceito fundamental.

\footnotetext{
Pode-se considerar um dos objetivos metodológicos deste trabalho demonstrar um materialismo histórico que aniquilou em si a idéia de progresso. Precisamente aqui o materialismo histórico tem todos os motivos para se diferenciar rigorosamente dos hábitos de pensamento burgueses. Seu conceito fundamental não é o progresso, e sim a atualização (BENJAMIN, 2007, p. 501 - N 2,2).
}

A atualização é tomada aqui enquanto leitura não linear, não aplainada, mas vertical da História. A atualização se dá como lampejo, em um momento de perigo, e permite a dialética entre 0 ocorrido e o presente.

Não é que o passado lança sua luz sobre o presente ou que o presente lança sua luz sobre o passado; mas a imagem é aquilo em que o ocorrido encontra o agora num lampejo, formando uma constelação. Em outras palavras: a imagem é a dialética na imobilidade. Pois, enquanto a relação do presente com o passado é puramente temporal e contínua, a relação do ocorrido com o agora é dialética - não é uma progressão, e sim uma imagem, que salta (BENJAMIN, 2007, p. $504-\mathrm{N}$ $2 a, 3)$.

\section{5 - Concepção de Experiência}

A barbárie típica da modernidade nos deixa pobres em experiências comunicáveis. Quando aceitamos a imposição da história oficial, nos desvinculamos de nossa história de luta e resistência cultural. Desse modo nos é restringido o acesso àquelas experiências que vão além da nossa individualidade e que apontam para uma sabedoria coletiva. É neste sentido que se pode afirmar que subtraídos de experiências comunicáveis tornamo-nos mais pobres.

O acesso a uma experiência de dimensão coletiva, próxima do que podemos chamar de sabedoria, torna vivo e fecundo o passado. Mas quando perdemos esta riqueza, o que nos 
resta? Quando nossa humanidade é diminuída diante do absurdo da exploração do homem pelo homem, o que nos resta? Então é preciso, como prova de nossa honradez, confessar nossa pobreza: "Sim, é preferível confessar que essa pobreza de experiência não é mais privada, mas de toda a humanidade" (BENJAMIN, 1994a, p.115). É preciso nessas circunstâncias ser bárbaro também. Mas ser bárbaro em um novo e positivo conceito.

Pois o que resulta para o bárbaro dessa pobreza de experiência? Ela 0 impele a partir para frente, a começar de novo, a contentar-se com pouco, a construir com pouco, sem olhar nem para a direita nem para a esquerda. Entre os grandes criadores sempre existiram homens implacáveis que operaram a partir de uma tabula rasa (BENJAMIN, 1994a, p. 115).

Para resistir à cultura que produz "amontoados de ruínas", numa "tempestade" que "chamamos de progresso", é preciso sermos criadores, bárbaros no bom sentido. São esses que

precisam instalar-se, de novo e com poucos meios. São solidários dos homens que fizeram do novo uma coisa essencialmente sua, com lucidez e capacidade de renúncia. Em seus edifícios, quadros e narrativas a humanidade se prepara, se necessário, para sobreviver à cultura. E o que é mais importante: ela o faz rindo. Talvez esse riso tenha aqui e ali um som bárbaro (BENJAMIN, 1994a, p. 115).

Em sua obra, Benjamin distingue duas concepções de experiência. Uma derivada da palavra alemã "Erfahrung", que se refere a um sentido coletivo, de uma dimensão compartilhada, a experiência bruta. A segunda deriva da palavra alemã "Erlebnis", que se opõe à primeira e significa vivência, experiência vivida, característica do sujeito solitário (GAGNEBIN, 1994), e traz uma cisão entre o intelectual e o místico. De acordo com Gagnebin (1994), nos textos fundamentais dos anos 1930, Benjamin

\footnotetext{
demonstra o enfraquecimento da "Erfahrung" no mundo capitalista moderno em detrimento de outro conceito, "Erlebnis", experiência vivida (...); esboça, ao mesmo tempo, uma reflexão sobre a necessidade de sua reconstrução para garantir uma memória e uma palavra comuns, malgrado a desagregação e esfacelamento do social (GAGNEBIN, 1994, p.9).
}

O enfraquecimento da "Erfahrung" acompanha, segundo Benjamin (1994c), 0 desaparecimento da figura do narrador. Aquele que, entre os sábios e mestres, recorre ao acervo de uma vida que vai além da sua experiência individual, "Erlebnis". Daí por que o uso da narrativa torna-se um elemento importante no método de pesquisa que toma Benjamin como referencial. Podemos entender que sua obra, assim como sua proposta metodológica, só pode ser realizada por uma postura bárbara, num sentido expresso anteriormente, e utilizando uma razão que não dispensa a riqueza da experiência humana. 
Tornar cultiváveis regiões onde até agora viceja apenas a loucura. Avançar com 0 machado afiado da razão, sem olhar nem para a direita nem para a esquerda, para não sucumbir ao horror que acena das profundezas da selva. Todo solo deve alguma vez ter sido revolvido pela razão, carpido do matagal do desvario e do mito (BENJAMIN, 2007, p. 499 - N 1,4).

Ao opor-se a razão iluminista Benjamin ressalta um caráter místico que abarca 0 conceito de experiência -"Erfahrung"-, que desconstrói a ilusão típica da verdade dos vencedores.

\section{Uma construção metodológica benjaminiana (Considerações sobre método e fonte)}

Cabe inicialmente fazer considerações sobre o nosso entendimento acerca da elaboração de um método de pesquisa. Consideramos que a metodologia faz parte de uma reflexão ampla, que está necessariamente relacionada com aquilo que aqui chamamos de alicerces epistemológicos. É, portanto, a concepção da metodologia que nos oferece um escopo de possibilidades de estratégias de ação específicas para cada investigação. As proposições teóricas e metodológicas devem estar intimamente relacionados. Por exemplo, um método derivado do referencial teórico de Walter Benjamin possui necessariamente uma forte implicação política, uma vez que os alicerces epistemológicos do qual ele é derivado aponta para uma não neutralidade. Dessa perspectiva resulta que a forma como lidamos com as fontes está inevitavelmente alicerçada por nossa visão de mundo, de história, de tempo etc. As estratégias próprias de cada investigação devem ser criadas e re-criadas. No entanto elas devem seguir princípios coerentes com uma discussão metodológica mais ampla.

Podemos compararmos o método com um rascunho sobre como vamos realizar nosso caminho de pesquisa. Ao longo do percurso este rascunho pode precisar ser refeito, e é preciso ser flexível para tal. A exemplo das cartas náuticas, que apesar de nos fornecerem uma série de informações úteis, não são suficientes para que possamos ter todas as respostas para as situações com que nos deparamos ao longo da navegação, o método não nos dá a priori todas as chaves de como chegar aos nossos objetivos de investigação. Às vezes nos deparamos com ventos que nos desviam da rota. São dificuldades em obter alguns dados ou mesmo de interpretá-los, informações sobre o sujeito da pesquisa que nos surpreendem, contextualizações que nos fazem perder de vista não só nossa rota, mas o próprio objetivo da pesquisa. Enquanto para uns isso pode ser entendido como desvios a indicar a necessidade de retomar o norte inicial do projeto, para outros as surpresas reservadas por "lansã"3 podem indicar uma nova rota a ser seguida. Essa ousadia de dar atenção aos desvios é própria dos grandes navegadores. Com essa metáfora podemos situar a postura metodológica de Benjamin:

3 Orixá das religiões afro-brasileiras, considerada como deusa das tempestades. 
Comparação das tentativas dos outros com empreendimentos de navegação, nos quais os navios são desviados do Pólo Norte magnético. Encontrar esse Pólo Norte. O que são desvios para os outros, são para mim os dados que determinam a minha rota. - Construo meus cálculos sobre os diferenciais de tempo - que, para outros, perturbam as "grandes linhas" da pesquisa. (BENJAMIN, 2007, p. 499 - N 1,2).

Grandes navegadores também são grandes narradores. Benjamin (1994c, p.199) reconhece que, junto com os camponeses, os marujos "foram os primeiros mestres da arte de narrar". Daí o termo diário de bordo, que na academia chamamos de diário de pesquisa. Nele temos a abertura para escrever tudo o que pensamos ao longo da nossa travessia.

Dizer algo sobre o próprio método da composição: como tudo em que estamos pensando durante um trabalho no qual estamos imersos deve ser-lhe incorporado a qualquer preço. Seja pelo fato de que sua intensidade aí se manifesta, seja porque os pensamentos de antemão carregam consigo um telos em relação a esse trabalho. (BENJAMIN, 2007, p. $499-\mathrm{N}$ 1,3).

Colocando em discussão os princípios peculiares a uma construção metodológica inspirada na obra de Walter Benjamin, podemos tomar como uma primeira orientação que 0 método a ser construído deve implicar sempre a desconstrução da linearidade histórica estabelecida pela historiografia tradicional. O historiador deve, pois, contribuir para a criação de outras histórias.

A virtude para o historiador, segundo Nietzsche (apud LÖWY, 2005, p. 73), "consiste em se opor à tirania do real, a 'nadar contra as ondas da história' e em saber lutar contra elas." Tal posicionamento nos direciona para a formulação de estratégias para lidar com histórias silenciadas, que apontam para ação de sujeitos oprimidos. Em Benjamin o historiador tem a responsabilidade de evitar o esquecimento, ou seja, evitar o silenciar definitivo das vozes que vêm do passado. É de se esperar que a maior parte dessas vozes venha de grupos que sobreviveram historicamente por conta da luta de resistência na preservação de seus costumes, valores, tradições etc. Na maioria das vezes as experiências vividas nessas lutas não são passadas para os documentos escritos, fazendo parte de um conhecimento que é transmitido oralmente.

Somos levados a reconhecer a importância do testemunho oral, que vai além do mero levantamento de informações. A história oral transmite uma experiência não só individual, mas sobretudo coletiva, no sentido que inclui as gerações passadas, e pode ser utilizada para problematizar os dados obtidos em pesquisas tradicionais em fontes escritas. Podemos trabalhar com a produção de narrativas, que podem apontar para acontecimentos específicos e de interesse da investigação, ou podem apontar para questões mais amplas de histórias de vida, e 
que necessariamente se relacionam com questões de caráter coletivo. Talvez alguém argumente que as histórias de vidas trazem detalhes desnecessários ao entendimento linear da história. Mas, como já foi dito, não é na linearidade que estamos interessados. Não cabe nos restringirmos à visão panorâmica, pois isso nos deixaria míopes. É bom caminhar de perto, atentar para o que os detalhes, aquilo que é considerado secundário, que é pouco visível, tem a nos dizer sobre o todo.

Mesmo uma simples notícia de jornal do século XIX, "garimpada" com muito suor, pode ser chave de um todo que está por ser montado. A história da educação não escapa a esse princípio: um diário de classe, ou mesmo o diário pessoal de um professor, um relatório de um diretor, arquivos escolares, a biografia de um educador ou mesmo uma foto dos alunos pode nos trazer o tão procurado detalhe que ilumina o todo.

\begin{abstract}
A primeira etapa desse caminho será aplicar à história o princípio da montagem. Isto é: erguer as grandes construções a partir de elementos minúsculos, recortados com clareza e precisão. E, mesmo, descobrir na análise do pequeno momento individual o cristal do acontecimento total. Portanto, romper com o naturalismo histórico vulgar, apreender a construção da história como tal. (BENJAMIN, 2007, p. 503 - N 2,6).
\end{abstract}

Ao trabalhar com fontes escritas, a partir das proposições de Benjamin, devemos saber que em grande parte das vezes eles servem para legitimar o poder de certos grupos, sendo instrumentos de barbárie. É fundamental que consideremos estes grupos oprimidos também como autores da história e que estejamos politicamente posicionados em relação às lutas que foram travadas e que certamente se perpetuam no presente. Fiquemos atentos ao fato de que a elaboração cultural, que resulta numa luta de resistência, normalmente não acontece nos espaços oficiais de educação. Tendem a fazer parte do âmbito da educação informal e a seguir, muitas vezes, princípios diferentes dos estabelecidos pelos grupos que estavam no poder.

Muitos dos aspectos históricos com que nos deparamos podem nos dar a impressão de que estão fora daquilo que se conhece como História. $E$ de fato estarão muitas vezes fora do curso dos acontecimentos tomados como padrão. Nesse caso, por mais que nos esforcemos para adicioná-los ao fluxo de causalidade, não obteremos êxito. Devemos então encarar nosso objeto histórico como uma totalidade revolucionária, exatamente por emancipar um passado oprimido que não tem espaço na rede da causalidade que interessa aos "donos da história." Tal lampejo do passado terá então sentido enquanto uma constelação construída no presente, e a partir de nosso posicionamento político.

A compreensão do sentido emancipador que damos ao passado deriva da concepção de jetztzeit, "o tempo do agora". O que dá a qualidade de um fato histórico é a constelação criada 
entre o presente e um acontecimento do passado, e na confrontação do acontecido enquanto concentrado da totalidade histórica. Desse modo, para Benjamin (1994b, p.232 - apêndice 1), "nenhum fato, meramente por ser causa, é só por isso um fato histórico. Ele se transforma em fato histórico postumamente, graças a acontecimentos que podem estar dele separados por milênios."

$\mathrm{Na}$ tese XVII, Benjamin propõe, em vez do procedimento aditivo, característico do historicismo, um princípio construtivo, que seria próprio de uma historiografia marxista. Neste princípio a aproximação do objeto histórico se dá quando há confrontação enquanto mônada, ou seja, enquanto concentrado da totalidade histórica. "Nessa estrutura, ele reconhece o sinal de uma imobilização messiânica dos acontecimentos, ou, dito de outro modo, de uma oportunidade revolucionária de lutar por um passado oprimido" (BENJAMIN, 1994b, p. 231).

Se um fato histórico só é assim considerado por conta de uma constelação que integra 0 presente, o resultado de nossas investigações jamais pode pretender fechar a história, fixar uma verdade atemporal.

É importante afastar-se resolutamente do conceito de "verdade atemporal". No entanto, a verdade não é - como afirma o marxismo - apenas uma função temporal do conhecer, mas é ligada a um núcleo temporal que se encontra simultaneamente no que é conhecido e naquele que conhece. Isto é tão verdadeiro que o eterno, de qualquer forma, é muito mais um drapeado em um vestido do que uma idéia (BENJAMIN, 2007, p. $505-\mathrm{N} 3,2$ ).

A ilusão de suprir um fenômeno histórico com todas as suas possibilidades de ser conhecido, ou resolvido, é dá-lo como morto. Pois somente enquanto forem preservadas novas possibilidades de interpretação, respeitando seu atributo místico, ele será considerado vivo.

\footnotetext{
Um fenômeno histórico, conhecido pura e completamente e resolvido em um fenômeno de conhecimento, é, para aquele que o conhece, morto: pois ele conheceu nele a ilusão, a injustiça, a paixão cega, e em geral todo o horizonte sombrio e terrestre desse fenômeno [...] (NIETZSCHE, 2000, p. 275).
}

O resultado de nossas investigações e a própria escrita histórica devem se realizar como abertura para novas interpretações a partir de novas constelações presentes. Nesta perspectiva historiográfica a investigação respeita o mistério presente no tempo e garante ao leitor e às gerações futuras a liberdade de interpretação, pois o passado, o presente e o futuro passam a existir em um mesmo agora. $O$ texto produzido pelo historiador deve possuir o caráter aberto de um conhecimento que se perpetua no tempo, superando o aspecto puramente informativo e fechado em si mesmo. 
"Nos domínios de que tratamos aqui, o conhecimento existe apenas em lampejos. 0 texto é o trovão que segue ressoando por muito tempo" (BENJAMIN, 2007, p. 499 - N 1,1). Esta também é a característica da narrativa, por isso seu uso é privilegiado em nossa construção metodológica.

O extraordinário e o miraculoso são narrados com a maior exatidão, mas o contexto psicológico da ação não é imposto ao leitor. Ele é livre para interpretar a história como quiser, e com isso o episódio narrado atinge uma amplitude que não existe na informação (BENJAMIN, 1994c, p. 203).

O que é próprio da narrativa, e podemos recuperar naqueles grupos oprimidos, é a faculdade de intercambiar experiências. "A experiência que passa de pessoa a pessoa é a fonte a que recorreram todos os narradores. $E$, entre as narrativas escritas, as melhores são as que menos se distinguem das histórias orais contadas pelos inúmeros narradores anônimos" (BENJAMIN, 1994c, p.198).

O acesso às narrativas é elemento importante na elaboração das estratégias metodológicas, pois elas nos dão acesso a uma comunidade de experiência, que partilha uma dada tradição. Este envolvimento, este partilhar de experiência é algo fundamental quando temos grupos tradicionais como sujeitos de nossas pesquisas. É preciso realizar esta aproximação, vivenciar detalhes que formarão a constelação do todo, partilhar experiências. São as experiências, no sentido de "Erfahrung", que preservam um caráter coletivo e que não podem ser encerradas à luz da razão iluminista, preservando sua sabedoria e novas possibilidades de interpretação.

A construção metodológica a partir da obra de Walter Benjamin nos mostra seu grande potencial de se aproximar da experiência dos sujeitos que constroem a história em seu cotidiano. "Benjamin estranha o mundo para encontrar o mistério no cotidiano e acolhê-lo na escrita" (NUNES, 2005, p. 96). Seus princípios metodológicos permitem que, ao mesmo tempo que 0 historiado mantém uma visão crítica da realidade, desenvolve sua capacidade criativa de lidar com seu objeto histórico. "Assim também o historiador hoje tem que construir uma estrutura filosófica - sutil, porém resistente, para capturar em sua rede os aspectos mais atuais do passado" (BENJAMIN, 2007, p. 501 - N 1a,1). De seus princípios metodológicos deriva a função do historiador, com forte implicação política. A proposta metodológica baseada em Benjamin visa realizar a desconstrução de uma história imposta e a criação de uma história que, apesar de toda força contrária impressa pelo processo civilizatório, dá espaço para um passado que clama por uma esperança transformadora no presente. 


\title{
4. Educação: da barbárie à redenção
}

A educação tende a ser vista como um instrumento que serve ao progresso da humanidade, e de fato ela sempre foi um ponto fundamental do nosso processo civilizatório. Não é a educação responsável pelo processo de transmissão cultural dos valores e verdades da classe opressora? Não é a educação que perpetua nas escolas a história dos vencedores? Que silencia nos jovens as vozes oprimidas no passado? Não é ela também responsável pelo processo ideológico que garante a divisão social entre dominadores e dominados? E luta de classe, também não é delegada a ela a tarefa de camuflá-la? Os livros oficiais não destroem do passado sua força revolucionária? A educação tem sido também ao longo dos séculos um instrumento de barbárie. E essa denúncia também é responsabilidade do historiador da educação.

\begin{abstract}
Nunca houve um monumento da cultura que não fosse também um monumento da barbárie. E, assim como a cultura não é isenta de barbárie, não o é, tampouco, 0 processo de transmissão da cultura. Por isso, na medida do possível, o materialismo histórico se desvia dela. Considera sua tarefa escovar a história a contrapelo (BENJAMIN, 1994b, p.225 - tese VII).
\end{abstract}

Entretanto, o processo de resistência cultural dos grupos oprimidos, a transmissão de sua cultura como processo de formação identitária também é uma forma de educação. Mas consideraremos este processo como educação informal, se ousarmos "escovar a história a contrapelo", escrevendo outra história da humanidade.

As contribuições da história da educação localizam-se sempre no presente, pois só aí é possível a redenção. Devemos abrir possibilidade de novas interpretações do mundo; criar a abertura para uma experiência que transcende a experiência individual, permitindo reinventar nossa humanidade; pensar, portanto, uma educação que se vincule à experiência. Os estudantes merecem ser encarados como autores da história, e não como meros reprodutores de informação. São sujeitos históricos e das tradições das quais se originam. $O$ espaço escolar pode ser um âmbito de recuperação da arte de narrar, resgatando professores e alunos como narradores.

A educação como processo de redenção só será possível se aprendermos a escapar da anestesia das formas opressoras de educação. A redenção nos coloca em ação no mundo.

Nesta perspectiva, compreendemos que o passado elaborado pela memória torna-se parte de um fazer histórico inacabado através de uma prática educativa politicamente emancipadora. "A educação teria, portanto, esse essencial não-acabamento" (NUNES, 2005, p. 96), impelindo os educadores para a ação atualizada. 


\section{Acerca do caminho experimentado (e por sucessivas re-invenções)}

As elaborações metodológicas expostas aqui partiram de uma compreensão inspirada na obra de Benjamin. Elegemos alguns princípios que encaramos como fundamentais para a presente construção. O primeiro deles é o "tempo do Agora" - Jetztzeit - de onde deriva que é no agora que o passado, o presente e o futuro se encontram, potencializando a ação revolucionária, aquela que nos faz criadores da história, ao invés de meros repetidores.

O segundo princípio é a dimensão teológica presente em toda sua obra e sem a qual não podemos compreendê-la. Fundamental destacarmos que, como Bolle (2007, p.1156) chama atenção, os conceitos "teológicos" de Benjamin, como a concepção "messiânica" da História, não são irracionais, visto que se originam "do embasamento de sua historiografia em uma filosofia da história e da linguagem".

A concepção de história nos é um ponto elementar. "Articular historicamente o passado não significa conhecê-lo "como ele de fato foi". Significa apropriar-se de uma reminiscência, tal como ela relampeja no momento de um perigo" (BENJAMIN, 1994b, p.224 - tese VI). Em Benjamin o passado surge como vozes que implicam uma atitude presente que desconstrói a idéia de linearidade e de falso progresso. Eis aqui o quarto princípio, a crítica à ideia de progresso tomada como uma expressão inimiga: "O dom de despertar no passado as centelhas da esperança é privilégio exclusivo do historiador convencido de que também os mortos não estarão em segurança se o inimigo vencer. E esse inimigo não tem cessado de vencer" (BENJAMIN, 1994b, p.223-224 - tese VI). O quinto princípio que alicerçou nossa construção metodológica foi a concepção de experiência, que aponta para a dimensão de uma sabedoria coletiva.

Assim como a própria história, consideramos nossa construção metodológica como merecedora de sucessivas re-invenções. São, pois, os caminhos de cada investigação que devem anunciar tal re-criação. Em cada caminhada os traços de vestígios de uma luta de resistência comunicam um passado aberto. Dialogam com palavras fortes que podem desconstruir a falsa continuidade linear do tempo. São vestígios que nos integram numa experiência que vai além de nós. Além do individualismo característico da modernidade. Tempo de uma sociedade capitalista, mergulhada cada vez mais numa experiência privada, pobre de um sentido coletivo.

Mas num movimento de resistência, de qualidade messiânica, relampeja uma sempre nova escrita da história. Com o poder de parar o tempo, ainda que em efemeridade, e destruir a ilusão do progresso. Ouça as vozes que vêm do passado. Historiadores, escutem as vozes que ecoam nestes traços arquitetônicos e nessa cultura em que carecemos mergulhar. As ruas pelas 
quais passam em suas investigações precisam preservar o misterioso poder da aura que nos permite ouvir as vozes daqueles que passaram por aqui. Este seu caminhar não é mais somente seu. Para conhecer das riquezas que fazem como historiadores, perguntem-se sobre as experiências comunicadas e do poder revolucionário que pode germinar nessa caminhada, que sempre foi coletiva, e inclui a gerações atual e as passadas.

Pois cuidado com a pragmática de uma matemática historiográfica, disfarçada de um materialismo objetivista, de um simplório mecanicismo vulgar. Cuidado, também, com aqueles que querem reduzir tudo a uma exclusividade teológica. Tudo isso os empobrece, uma vez que os impede de ver a dialética entre o marxismo e a teologia.

A educação, como processo histórico que constrói nossa identidade, precisa ser reconhecida fora dos trilhos do progresso para que não sejamos passageiros conformados com nosso destino. Na contramão do que não queremos, é possível firmar o caminho a ser percorrido.

Lá vem o trem e vocês sabem que ele não quer que se olhe para trás; quer levar a crer que existirá sempre um caminho lógico. Mas dentro de um presente atualizado pode haver uma explosão e seu descarrilamento. 0 destino não está naturalizado, a não ser que acreditem nisso. Olhem o destino do bilhete da passagem que carregam no bolso. Ele é falso. Ele ainda não existe; reconheçam aí nossa força. Não creiam na fatalidade, pois isso também é combustível para o progresso. Madeira dos casarões antigos, dos monumentos históricos, madeira de lei queimada, num típico ato de violência de quem escreve a história final.

Prefiram ir andando por todo o espaço. E pelas ruas também. $O$ tempo de caminhar é agora. Antes que derrubem ou renovem toda arquitetura que nos cercam. Antes que a funcionalidade cale as vozes que se quer ouvir. Antes que os vidros se edifiquem como símbolos de nossa pobreza.

A história de nossa educação precisa ser contada com vozes de negros, índios, judeus, brancos pobres, ciganos e todos mais de quem se deve chegar perto para reconhecer. As narrativas estão fora desses trilhos e elas têm muito para contar, têm experiências para comunicar. Vamos então caminhando, para depois quem sabe navegar. $E$ talvez queiramos tirar os sapatos, ou mesmo trocá-los. Viajantes nos tornemos. E seremos educados nesse processo e apresentados a nos mesmos, como sujeitos coletivos.

\section{REFERÊNCIAS BIBLIOGRÁFICAS}

1. BELO, Rafael A. Espiritualidade: dialógica e experimental. A perspectiva da psicologia fenomenológica existencial diante da espiritualidade humana. Maceió: Edufal, 2008. 
2. BENJAMIN, Walter. Experiência e pobreza. In.: Magia e técnica, arte e política: ensaios sobre literatura e história da cultura. Tradução de Sérgio Paulo Rouanet. 7.ed. São Paulo: Brasiliense, 1994a. p. 114-119.

$3 . \quad$ Sobre o conceito da história. In.: Magia e técnica, arte e política: ensaios sobre literatura e história da cultura. Tradução de Sérgio Paulo Rouanet. 7.ed. São Paulo: Brasiliense, 1994b. p. 222-232

4. $\quad$ O $O$ narrador. Considerações sobre a obra de Nikolai Leskov. In.: Magia e técnica, arte e política: ensaios sobre literatura e história da cultura. Tradução de Sérgio Paulo Rouanet. 7.ed. São Paulo: Brasiliense, 1994c. p. 197-221

5. . N - Teoria do Conhecimento, Teoria do Progresso. In: Passagens. Belo Horizonte: EditoraUFMG; São Paulo: Imprensa Oficial do Estado de São Paulo, 2007. p. 499 - 530

6. BOLLE, Willi. "Um painel dom milhares de lâmpadas". Metrópole e Megacidade. In.: BENJAMIN, Walter. Passagens. Belo Horizonte: Editora UFMG; São Paulo: Imprensa Oficial do Estado de São Paulo, 2007. p. 1141 - 1159

7. BUBER, Martin. Eu e Tu. $2^{\mathrm{a} e d}$. São Paulo: Cortez \& Moraes, 1979.

8. FONSECA, Afonso Lisboa da. Nietzsche e a História. Notas da Palestra ministrada na disciplina Historiografia da Educação, do Mestrado em Educação Brasileira da Ufal. Maceió, 2008.

9. GAGNEBIN, Jeanne Marie. Prefácio. Walter Benjamin ou a história aberta. In: BENJAMIN, Walter. Magia e técnica, arte e política: ensaios sobre literatura e história da cultura. Tradução de Sérgio Paulo Rouanet. 7.ed. São Paulo: Brasiliense, 1994. p. 7-19

10. LÖWY, Michael. Walter Benjamin: um aviso de incêndio. Uma leitura das teses "Sobre 0 conceito de história." São Paulo: Boitempo, 2005

11. NIETZSCHE, F. W. Considerações Extemporâneas II - Da utilidade e desvantagem da história para a vida. In.: .Obras Incompletas. São Paulo: Nova Cultural, 2000. p. $273-287$

12. NUNES, Clarice. Walter Benjamin: os limites da razão. In.: FARIA FILHO, L. M. (org.) Pensadores sociais e História da Educação. Belo Horizonte: Autêntica, 2005. p.87-98 